\title{
Editorials
}

\section{Mental health care in hospitals and primary care:}

\author{
an unsustainable balance
}

\section{INTRODUCTION}

When the NHS was created in the UK in 1948, over half of its 240000 inpatient beds were psychiatric. ${ }^{1}$ Bed numbers increased to a peak of almost 150000 in 1955 in England, but with the development of effective antipsychotic medications like chlorpromazine ${ }^{2}$ doctors could safely care for more patients in the community.

Recent research on data from the Health and Social Care Information Centre and published Hospital Episode Statistics has shown that psychiatric bed numbers in England have fallen dramatically to just over $20000^{3}$ and are continuing to fall. The number of mental health beds fell by 39\%, from 37000 in 1998 to 22300 in 2012. This effectively limits the ability to admit people with mental illness. Not since the mid-1800s have bed numbers been so low. Consequently, admissions to mental health beds for key mental disorders are capped. Hospital admissions for depression, bipolar disorder, schizophrenia, and dementia have all fallen significantly. The strongest decline, for depression, involved 1000 fewer admissions each year, with increasingly shorter lengths of stay.

Although the overall psychiatric bed numbers have fallen, Mental Health Act detentions on admission have increased by almost 300 per year between 1998 and 2012 (linear regression of detentions over time: $\beta$ $=298, P<0.011$.

Across NHS England (for all hospital beds, not just mental health) alcoholrelated admissions (for example, delirium or dependence) have increased strongly, by more than 1700 extra every year ( $\beta=1764)$, and this increase is significantly associated with increasing liver fibrosis and cirrhosis admissions (Pearson's $r=0.89, P<0.001$ ) across the NHS and the affordability of alcohol (Pearson's $r=0.76, P<0.01)^{3}$

The diminishing reserve of available NHS psychiatric beds and falling admission rates strongly implies that there is an

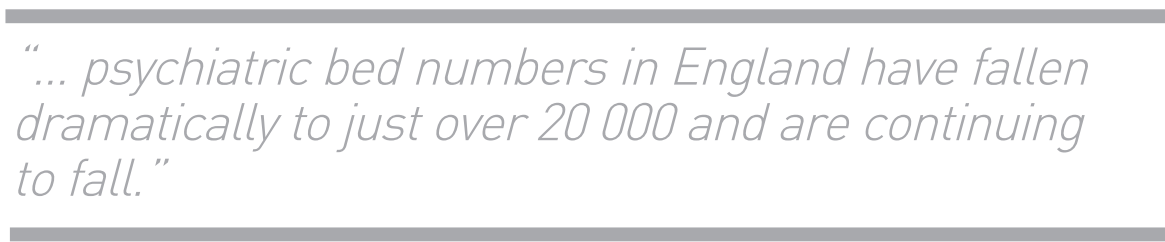

increased number of more severe cases of mental illness within the community either diagnosed and treated, or unrecognised and untreated.

The negative impact of fewer beds would be mitigated if secondary care community mental health services are diagnosing, treating, and managing more cases of mental illnesses within the community. However, there is a relative lack of any data on community treatment comparable to the assiduously collected national data set of Hospital Episode Statistics. ${ }^{2}$ What evidence is available on Crisis Resolution Team activity suggests that there has been no increase in open caseloads to compensate for the diminishing admission rates.

\section{A LACK OF EVIDENCE FOR COMMUNITY TEAMS}

Despite wholesale changes in the way that mental health care is delivered, the evidence base for those changes in terms of community teams is worryingly slim. A recent systematic review of crisis intervention for severe mental illness found just six studies evaluating the effect of community crisis teams on 984 patients and judged their methodology to be "poor'. ${ }^{4}$ These six studies excluded service users with alcohol or drug misuse, or those in danger of harming themselves or others, and so are atypical of populations managed by community teams in England.

The NHS Mental Health National Service Framework (MHNSF), published in 1999 , had envisaged that crisis intervention teams would perhaps prevent 30\% of mental health admissions ${ }^{5}$ and that

\section{"What is required is a policy review and further epidemiological study of morbidity, mortality, and health needs associated with mental disorder in the community.}

crisis intervention teams represented 'an alternative to inpatient care,' and also that assertive outreach teams would 'reduce hospital admissions'. ${ }^{6}$ These positive predictions do not mirror the experience of integrated community care teams more generally, which is that, despite intensive and targeted input, they do not reduce hospital admissions or overall costs. If admission rates are primarily being reduced by relentless cuts in bed numbers rather than any demonstrable increase in team activity or specific admission avoidance interventions, this begs the question as to who is really picking up the burden of treating people who were once deemed so ill they needed to be in hospital?

A realistic conclusion may be drawn that it must be primary care that now carries the excess burden of recognising and treating severe mental disorder caused by the decline in hospital provision.

\section{PATIENTS WITH SEVERE DEPRESSION AT SPECIAL RISK}

There may be significant needs, especially of patients with depression, not being met by community and primary care services. Almost all of the $20 \%$ of adults who experience anxiety or depression are now managed in primary care, which is incentivised to diagnose and treat through the Quality and Outcomes Framework. Despite this, there is doubt about the accuracy of diagnostic questionnaires, uncertainty about the use of drug treatment in mild to moderate depression, and a lack of alternative treatment strategies such as cognitive behavioural therapy (CBT), lalthough the government's Improving Access to Psychological Therapies [IAPT] programme is seeking to redress this). GPs simply do not have the time or resources to provide comprehensive care for people with depression.

\section{EPIDEMIOLOGICAL STUDY OF MENTAL HEALTH NEEDS}

What is required is a policy review and 


\section{"... the wholesale closure of NHS psychiatric beds \\ must be reversed.}

further epidemiological study of morbidity, mortality, and health needs associated with mental disorder in the community. We desperately need data on the prevalence and severity of various mental disorders, how they are being treated, if at all, and the unmet needs of these patients and their families. If primary care is to be the future major source of treatment for mental health disorders then a more extensively trained GP may be required, with the back-up of an easily coordinated response from fully trained and adequately resourced multidisciplinary teams within primary care. This will deliver user-friendly psychiatric care to meet the real needs of patients and their families.

Although austerity is now a major political and social driver, both to an increased disease burden and resource inertia, there may now be a case for saying that the wholesale closure of NHS psychiatric beds must be reversed. In addition to investment in effective primary care mental health services, we may also need more mental health beds. Evidence for this view might be strengthened by a national epidemiological study of mental health needs. If we, as a country, truly need a change of mental health policy, is there a political appetite to make this necessary change before a public health disaster becomes inevitable?

\section{Ben Green,}

Consultant Psychiatrist and Director, Institute of Medicine, University of Chester, Chester.

\section{Bill WJ Gowans,}

GP and Vice-Chair, Shropshire CCG, Shrewsbury.

\section{Provenance}

Commissioned; not externally peer reviewed.

DOI:10.3399/bjgp15X683365

\section{ADDRESS FOR CORRESPONDENCE}

\section{Ben Green}

Consultant Psychiatrist and Director, Institute of Medicine, University of Chester, Parkgate Road, Chester. $\mathrm{CH} 1$ 4BJ.

E-mail: doctorbengreen®ame.com

\section{REFERENCES}

1. Gregory RL. The Oxford companion to the mind. 2nd edn. Oxford: OUP, 2004

2. Ban TA. Fifty years chlorpromazine: a historical perspective. Neuropsychiatr Dis Treat 2007: 3(4): 495-500.

3. Green BH, Griffiths EC. Hospital admission and community treatment of mental disorders in England from 1998 to 2012. Gen Hosp Psychiatry 2014; 36(4): 442-448.

4. Murphy S, Irving CB, Adams CE, Driver R. Crisis intervention for people with severe mental illnesses. Cochrane Database Syst Rev 2012; 5: CD001087.

5. The Sainsbury Centre for Mental Health The NHS plan. A plan for investment. A plan for reform. Briefing II. http://wnw. centreformentalhealth.org.uk/pdfs/ briefing_11.pdf (accessed 18 Dec 2014).

6. Department of Health. The mental health policy implementation guide. http://wnw. wales.nhs.uk/sites3/Documents/776/ CRHT\%2OPIG.pdf (accessed 18 Dec 2014). 